\title{
Seroprevalence of Brucella infection and associated factors among pregnant women receiving antenatal care around human, wildlife and livestock interface in Ngorongoro ecosystem, Northern Tanzania. A cross-sectional study
}

Robert Makala ${ }^{1 \dagger}$, Mtebe V. Majigo $^{2^{*}+} \mathbb{D}$, George M. Bwire ${ }^{3}$, Upendo Kibwana ${ }^{2}$, Mariam M. Mirambo $^{4}$ and Agricola Joachim²

\begin{abstract}
Background: Brucellosis is a zoonotic disease transmitted to humans through contact with infected animals, animal products or consumption of infected dairy products. Brucella infection during pregnancy is of special interest due to association with adverse pregnancy outcomes. This study determined the seroprevalence and factors associated with Brucella infection among pregnant women around the human-wildlife-livestock interface area in Ngorongoro ecosystem, Northern Tanzania.

Methods: A facility-based cross-sectional study was conducted between May and June 2018 at six health facilities that provide antenatal services. Pregnant women receiving antenatal care were invited to participate. A structured questionnaire was used to collect socio-demographic and obstetric characteristics in addition to behavior and practices related to the occurrence of human brucellosis. The presence of serum immunoglobulin against Brucella was determined using Rose Bengal Plate Test (RBPT). The positive samples were further assayed for the presence of IgG and IgM using The enzyme-linkedimmunosorbent assay. Bivariate analysis was conducted to determine the variables associated with Brucella seropositivity. Multivariable logistic regression analysis was performed to examine the factors independently associations with Brucella seropositivity after adjustment for other explanatory variables.

Results: A total of 313 participants were enrolled in the study. The overall seroprevalence of Brucella infection was 10.9\% (34/313) determined by Rose Bengal plate test. Of 34 positive individuals, 27(79.4\%) and 8(23.5\%) were positive in the ELISA specific for IgG and IgM Brucella antibodies respectively. Regular contact with manure (AOR $3.16,95 \% \mathrm{Cl} 1.27-7.83$ ) and preference for animal fresh milk (AOR 3.80, 95\% Cl 1.23-11.69), raw meat (AOR 2.58, 95\% $\mathrm{Cl} 1.14-5.81$ ) and raw animal blood (AOR 2.71,95\% Cl 1.15-6.35) increased the odds of being Brucella seropositive. Contact with the animal placenta were not associated with Brucella seropositivity after adjustment.

(Continued on next page)
\end{abstract}

* Correspondence: mmajigo@gmail.com

${ }^{\dagger}$ Robert Makala and Mtebe V. Majigo contributed equally to this work.

${ }^{2}$ Department of Microbiology and Immunology, Muhimbili University of

Health and Allied Sciences, Dar es Salaam, Tanzania

Full list of author information is available at the end of the article

(c) The Author(s). 2020 Open Access This article is distributed under the terms of the Creative Commons Attribution 4.0 International License (http://creativecommons.org/licenses/by/4.0/), which permits unrestricted use, distribution, and reproduction in any medium, provided you give appropriate credit to the original author(s) and the source, provide a link to the Creative Commons license, and indicate if changes were made. The Creative Commons Public Domain Dedication waiver (http://creativecommons.org/publicdomain/zero/1.0/) applies to the data made available in this article, unless otherwise stated. 
(Continued from previous page)

Conclusion: This study has found that brucellosis is an important public health problem among pregnant women in areas with interactions of humans; livestock and wildlife. The risk of infection increased with the regular contact with manure and preference of raw foodstuffs like animal blood, meat, and milk. We emphasize the need for interventional strategies to reduce the risk of exposure.

Keywords: Infection, Pregnancy, Brucellosis, Seroprevalence, Tanzania

\section{Background}

Brucellosis is one of the neglected zoonotic diseases, acquired through contact with infected animals, consumption of infected dairy products, or inhalation of aerosols $[1,2]$. Wildlife animals near human and domestic animal may act as reservoirs to both [3]. Veterinarians, livestock farmers, milkers, abattoir workers and laboratory workers are occupations at high risk of getting Brucella infection $[4,5]$. Exposure of wildlife animals to Brucella abortus in the Ngorongoro ecosystem has reached 24 and $17 \%$ for buffalo and wildebeest populations respectively [6]. The prevalence of brucellosis in domestic ruminants freerange grazing system in Ngorongoro conservation was found to range from 3 to $14.28 \%$ in different animals [7].

The community health significance of Brucella infection in humans is a severely devastating disease that requires prolonged treatment and may end with disabling results [8]. The major challenge is the similarity of clinical presentation to other febrile illnesses such as malaria and typhoid fever. Consequently, under-reporting and mismanagement may be common in areas with limited laboratory diagnosis $[9,10]$. Infection in pregnancy is of major public concerns as it associate with several detrimental pregnancy outcomes like spontaneous abortion, preterm delivery, and fetal death $[1,2,4,8]$. The risk of low birth weight has been demonstrated to be higher in pregnant women infected with Brucella [8]. The major burden of brucellosis is mostly seen in poor individuals living in close contact with animals and having poor access to health care service [11].

Previous studies conducted in Tanzania have reported up to $13 \%$ prevalence of brucellosis in the area of pastoral and agro-pastoral communities [11, 12]. However, there is limited published data regarding Brucella infections among pregnant women in Tanzania, especially in the area of interactions of humans, livestock and wildlife. This limited information highlights the need to determine the seroprevalence of Brucella infection and associated modifiable factors among pregnant women. The information generated from this study may be of help for policy and interventional strategies. Ngorongoro was selected as the study area based on the presence of high interactions among the human-animal-wildlife interface which could play a role in the maintenance of the disease.

\section{Methods \\ Study design and setting}

This was a facility-based cross-sectional study conducted between May and June 2018 in Ngorongoro District, Arusha region of Northern Tanzania. The district plays host to parts of the wildebeest migration at the same time cattle, goat and sheep rearing is a common practice. The population of the Ngorongoro District is around 130,000 and the major ethnic groups are the Masai and Sonjo.

The Ngorongoro District has 20 public health facilities including 14 dispensaries, four health centres, and two hospitals. Each of the two hospital records between 25 and 40 new antenatal clinic attendances per week. The study involved six health facilities that provide antenatal services including: Wasso designated district hospital, Sakala and Loliondo health centers as well as Muholo, Sale, and Samunge dispensaries.

\section{Study population, sample size, and sampling procedure} Pregnant women attending the antenatal clinic at selected health facilities were invited to participate in the study. The study enrolled pregnant women who lived in the study area for more than 3 months and accepting to participate by signing written informed consent were enrolled. The sample size was estimated using Kish Leslie formula [13], at 95\% confidence interval (CI) considering 7.7\% seroprevalence of Brucella infection in Arusha Tanzania [12] and a 3\% margin of error. Eligible clients were consecutively enrolled in the study until reaching a representative sample size.

\section{Data collection}

A structured questionnaire (Additional file 1) was used to collect the required information from each participant. Data for socio-demographic and obstetric characteristics included: age, marital status, education level, occupation, location, gestation age, gravidity, parity and history of spontaneous abortion. Factors with potential risk for Brucella transmission related to animal care, animal product consumption and presence or absence of exposure at the individual level were also collected. The questionnaire included contact with animals and animal products, involvement in milking, sharing water sources with animals, assisting animals to give birth or drink animal fresh milk. 


\section{Study variables}

The dependent variable was Brucella serostatus as defined using the Rose Bengal Plate Test result and independent variables were behavior and practices with potential risk for Brucella infection. Regular contact with animal manure was defined as unprotected exposure to manure at least once in every week in the past 3 months. Participants were counted to contact the placenta if assisted animals giving birth at least once in the past 3 months. Washing animals at home was counted when performed at least once every week for 3 months. Preference of foodstuffs like animal fresh milk, raw animal blood, and raw meat was defined as consumption of the same at least once every week in the past 3 months.

\section{Specimen collection}

Experienced health personnel working at the facilities collected $4 \mathrm{ml}$ of venous blood aseptically using a plain vacutainer system. The collected specimens were labelled with the specific participant's identification number. Serum samples were separated from whole blood by centrifugation at $3000 \mathrm{rpm}$ for $5 \mathrm{~min}$. The specimens were kept at room temperature for $30 \mathrm{~min}$ then at 2$8{ }^{\circ} \mathrm{C}$ up to $24 \mathrm{~h}$ before processing.

\section{Laboratory procedure \\ Rose Bengal plate test}

The Brucella serology was first determined by Rose Bengal Plate Test (RBPT) a rapid agglutination test as previously described [14]. The test does not differentiate antibodies against different Brucella species like Brucella abortus and Brucella melitensis. Briefly, a drop of serum $(50 \mu \mathrm{l})$ was taken using a clean micro-pipette onto the test plate beside an equal $(50 \mu \mathrm{l})$ drop of RBPT antigen. The drops of serum and antigen were mixed using applicator stick then rocked manually for $4 \mathrm{~min}$ before examination. The presence of any visible reaction was considered to be positive [15].

\section{Enzyme-linked Immunosorbent assay}

Positive samples were kept at minus $20^{\circ} \mathrm{C}$ before transportation to the reference laboratory in Dar es Salaam for the detection of Immunoglobulin $M$ and $G$ antibodies. The commercially available test kits of enzymelinked immunosorbent assay (ELISA), SERION ELISA classic Brucella IgG/IgM/IgA (Institut Virion/Serion $\mathrm{GmbH}$ ) was used to detect IgM and IgG antibodies. The technique was performed according to the instructions from the manufacturer. In brief, $100 \mathrm{ml}$ of diluted serum samples and ready to use control were added to the micro test wells containing antigen. The assays were then incubated at $37^{\circ} \mathrm{C}$ for $60 \mathrm{~min}$, after which the first wash was performed. Later, anti-human IgM or IgG conjugated with an enzyme was added and incubated for 30 min at $37^{\circ} \mathrm{C}$. All wells were washed to remove excess conjugate, followed by a new incubation for $30 \mathrm{~min}$ at $37^{\circ} \mathrm{C}$ with the enzyme-substrate. Finally, the reaction was stopped by adding $100 \mathrm{ml}$ of stopping solution. The enzyme reaction with the Substrate yields a coloured product. The colour intensity is proportional to the amount of specific antibody and can be measured by the photometric method.

\section{Data analysis}

Categorical variables were summarized as frequencies and proportions while continuous variables were summarized as median and inter-quartile range (IQR). Group differences were examined using Pearson's Chisquare test. Bivariate analysis was conducted to determine the variables associated with Brucella seropositivity and crude odds ratio (cOR) with 95\% CI. Multivariable logistic regression was performed to examine the associations between the outcome variable and independent variables after adjustment for other variables as fixed effect and the cluster variable facility as random effect. Likelihood ratio tests (LRT) was used to simplify the final multivariable model so that only variables that are significantly associated with the outcome are retained in the final model. Associations in the multivariable logistic models were presented as adjusted odds ratios (AOR) with $95 \%$ CI. Interactions between independent variables were examined, and the Wald test was used to test the associations of the variables and interactions. The Hosmer-Lemeshow test was used to examine the overall fitness of the model. Statistical Package for Social Sciences version 23 was used for all data analyses. The level of significance was specified at 0.05 .

\section{Results}

\section{Characteristics of participants and seropositivity of Brucella infection}

A total of 313 participants were enrolled in the study, the median age was 25 years, interquartile range 20-30 years. The majority 299 (95.5\%) were Agro-pastoralists, 150 (47.9\%) had no formal education, 288 (92.0\%) were married, and $201(64.2 \%)$ had $\leq 28$ weeks of gestation. Out of 237 with prior pregnancies, 35 (14.8\%) reported a history of spontaneous abortion.

All participants were screened for antibodies against y Brucella using a rapid RBPT test. Out of 313 participants, 34(10.9\% [7.9-14.8]) were seropositive. Of 34 seropositive individuals, $27(79.4 \%)$ and $8(23.5 \%)$ were positive in the ELISA specific for IgG and IgM antibodies respectively. Based on the detection of IgM antibodies, 2.6\% (8/313) of participants were deemed to have had recent Brucella infection. The seropositivity observed for demographic (age, occupation, education level, marital status) and obstetric characteristics (gestation age, number of pregnancies, 
history of spontaneous abortion) were not significantly different $(p>0.05)$ (Table 1).

\section{Behavior and practice associated with Brucella infection} Several factors with the potential risk of brucellosis among humans were assessed and reported in Table 2. Participants who reported to have been exposed to the assessed potential risk factors; had more seropositive cases of Brucella except for those reported washing animals at home. At bivariate analysis, regular contact with animal manure increased the probability of Brucella seropositivity (cOR 2.7, 95\%CI 1.12-6.33). Contact with animal placenta through assisting of parturition had higher odds of being seropositive (cOR 3.1, 95\%CI 1.188.37). Preference for animal fresh milk, raw meat, and raw animal blood, were significantly associated with seropositivity to Brucella $(p<0.05)$. The odds of being seropositive among those prefer animal fresh milk, raw meat and raw animal blood ranged from 2.1 to 3.1 (Table 2). Washing animal at home $(p=0.4)$ and Sharing

Table 1 Descriptive characteristic of participants and Brucella seropositivity based on rapid RBPT

\begin{tabular}{|c|c|c|c|}
\hline Variable & Frequency & Seropositivity N (\%) & $P$-Value* \\
\hline Overall-seropositivity & 313 & $34(10.9)$ & \\
\hline \multicolumn{4}{|l|}{ Age group (years) } \\
\hline$\leq 25$ & 160 & 16(10.0) & \multirow[t]{2}{*}{0.616} \\
\hline$>25$ & 153 & 18(11.8) & \\
\hline \multicolumn{4}{|l|}{ Occupation } \\
\hline Agro-pastoralist & 299 & $31(10.4)$ & \multirow[t]{2}{*}{0.194} \\
\hline Formal employment & 14 & $3(21.4)$ & \\
\hline \multicolumn{4}{|l|}{ Level of education } \\
\hline Informal & 150 & $11(7.3)$ & \multirow[t]{3}{*}{0.054} \\
\hline Primary & 98 & $11(11.2)$ & \\
\hline Secondary and above & 65 & $12(18.5)$ & \\
\hline \multicolumn{4}{|l|}{ Marital status } \\
\hline Single & 25 & $4(16.0)$ & \multirow[t]{2}{*}{0.389} \\
\hline Married & 288 & $30(10.4)$ & \\
\hline \multicolumn{4}{|l|}{ Gestation age (weeks) } \\
\hline$\leq 28$ & 201 & $24(11.9)$ & \multirow[t]{2}{*}{0.412} \\
\hline$>28$ & 112 & $10(8.9)$ & \\
\hline \multicolumn{4}{|l|}{ Previous pregnancy } \\
\hline 0 & 76 & $8(10.5)$ & \\
\hline 1 & 76 & $9(11.8)$ & \multirow{3}{*}{0.421} \\
\hline 2 & 58 & $3(5.2)$ & \\
\hline $3+$ & 103 & 14(13.6) & \\
\hline \multicolumn{4}{|c|}{ Spontaneous abortion $(n=237)$} \\
\hline No & 202 & 20(9.9) & \multirow[t]{2}{*}{0.206} \\
\hline Yes & 35 & $6(17.1)$ & \\
\hline
\end{tabular}

${ }^{*} P$ value according to Pearson Chi-Square test
Table 2 Bivariate analysis of factors associated with Brucella seropositive

\begin{tabular}{|c|c|c|c|c|c|}
\hline Variable & Frequency & Seropositive N (\%) & $\mathrm{cOR}$ & $95 \% \mathrm{Cl}$ & $P$-value \\
\hline \multicolumn{6}{|c|}{ Regular contact with manure } \\
\hline Yes & 192 & $27(14.0)$ & 2.7 & $(1.12-6.33)$ & 0.022 \\
\hline No & 121 & $7(5.8)$ & 1 & & \\
\hline
\end{tabular}

Contact with animal placenta

$\begin{array}{llllll}\text { Yes } & 210 & 29(13.8) & 3.1 & (1.18-8.37) & \mathbf{0 . 0 1 7} \\ \text { No } & 103 & 5(4.9) & 1 & & \end{array}$

Washing animal at home

$\begin{array}{llllll}\text { Yes } & 201 & 20(10.0) & 0.8 & (0.37-1.59) & 0.487 \\ \text { No } & 112 & 14(12.5) & 1 & & \end{array}$

Preference for fresh milk

$\begin{array}{llllll}\text { Yes } & 229 & 30(13.1) & 3.0 & (1.03-8.83) & \mathbf{0 . 0 3 6} \\ \text { No } & 84 & 4(4.8) & 1 & & \end{array}$

Preference for raw meat

$\begin{array}{llllll}\text { Yes } & 76 & 13(17.1) & 2.1 & (1.01-4.48) & \mathbf{0 . 0 4 4} \\ \text { No } & 237 & 21(8.9) & 1 & & \end{array}$

Preference for raw animal blood

$\begin{array}{llllll}\text { Yes } & 174 & 26(14.9) & 2.9 & (1.26-6.57) & \mathbf{0 . 0 0 9} \\ \text { No } & 139 & 8(5.8) & 1 & & \end{array}$

Sharing water source with animal

$\begin{array}{llllll}\text { Yes } & 160 & 18(11.3) & 1.1 & (0.53-2.21) & 0.822\end{array}$

No $153 \quad 16(10.5)$

1

Key: $C O R$ Crude odds ratio, $\mathrm{Cl}$ Confidence Interval, $P$-value according to Pearson Chi-Square test

water source with the animal $(p=0.82)$ were not associated with seropositivity to Brucella.

Table 3 shows the result of final model of multivariable regression analysis performed to measure the relationship between Brucella seropositivity and independent variables. Variables that showed significant association $(p<0.05)$ in the bivariate analysis were included. Variables with significant LRT were retained in the final multivariable model. The multivariate logistic regression analysis revealed that regular contact with manure, preference for raw animal blood, preference for raw meat, and preference for animal fresh milk remained a risk factor for Brucella seropositivity (Table 3). Contact with placenta was not significantly associated with Brucella seropositivity after adjustment for other factors (AOR 1.99, 95\% CI 0.64-6.28.1, $p=0.219$ ).

The significance of odds ratio at $5 \%$ level for all variables in the multivariable model did not change after including facility variable to adjust for cluster random effect. Potential interactions between contact with manure and contact with placenta as well as, preference for raw meat and preference for raw animal blood on the outcome of Brucella seropositivity were found not significant. Based on these observations the interaction terms were drooped in the final model. The Hosmer- 
Table 3 Multivariable analysis of factors associated with the RBPT seropositivity of participants

\begin{tabular}{|c|c|c|c|c|}
\hline Variable ( ${ }^{*}$ P-value) & Seropositive N (\%) & AOR & $95 \% \mathrm{Cl}$ & ${ }^{* *} P$ value \\
\hline \multicolumn{5}{|c|}{ Regular contact with manure $(p=0.007)$} \\
\hline Yes & $27(14.0)$ & 3.16 & $1.27-7.83$ & 0.013 \\
\hline No & $7(5.8)$ & 1 & & \\
\hline \multicolumn{5}{|c|}{ Preference of raw milk ( $p=0.008)$} \\
\hline Yes & $30(13.1)$ & 3.80 & $1.23-11.69$ & 0.020 \\
\hline No & $4(4.8)$ & 1 & & \\
\hline \multicolumn{5}{|c|}{ Preference of raw meat $(p=0.025)$} \\
\hline Yes & $26(14.9)$ & 2.58 & $1.14-5.81$ & 0.022 \\
\hline No & $8(5.8)$ & 1 & & \\
\hline \multicolumn{5}{|c|}{ Raw blood consumption $(p=0.016)$} \\
\hline Yes & $26(14.9)$ & 2.71 & $1.15-6.35$ & 0.022 \\
\hline No & $8(5.8)$ & 1 & & \\
\hline
\end{tabular}

Key: $A O R$ Adjusted odds ratio, $C l$ Confidence interval * $P$-value according to Likelihood Ratio Tests, ${ }^{* *} P$-value according to wald test

Lemeshow test result was $p=0.438$ which indicated the fitness of the overall model.

\section{Discussion}

The current study has demonstrated a higher (10.9\%, [7.9-14.8]) seropositive of Brucella in pregnant women compared to the previous reports in the general population of the same geographical location $[12,16]$. Besides, the study has revealed nearly $3 \%$ of pregnant women with immunologic evidence of recent Brucella infection based on IgM ELISA. The level of seropositive found among pregnant women in the Ngorongoro District suggests that Brucella infection is a public health problem. Our finding is higher compared to a previous report from Pakistan (5.8\%) among pregnant women [4] but comparable to report from Nepal (11.25\%) among pregnant women [17]. Besides, our study finding is lower compared to a report from Uganda (17\%) in agro-pastoral communities [18] and 25\% among women with abortion in Rwanda [2].

The community where the present study was conducted comprised around 95\% agro-pastoralists. In most of the agro-pastoralist communities, women do most of the work associated with care and harvest of livestock products. They actively engage in barn cleaning, herding small ruminants, milking and preparing manure dung [19]. The seroprevalence found in the studied population can be explained by increased risk of exposure due to their routine activities [5]. Brucellosis being an endemic disease in humans and animals $[11,20]$ and the proximity of population to livestock-wildlife can also contribute to high seroprevalence observed.

The higher seropositivity of Brucella infection among pregnant women showed by this study could be attributed in part due to the preference for raw foodstuffs like fresh milk, raw meat, and raw animal blood. Eating habits may expose an individual to Brucella infection if the consumed products from infected livestock are not properly prepared $[12,18,21,22]$. A substantial number of participants in the current study reported a preference for animal fresh milk (73.2\%), preference for raw meat (24.3\%) and preference for raw animal blood (55.6\%). The habits of consumption of raw foodstuff were the risk factors independently associated with Brucella infection among pregnant women in Ngorongoro District. Our findings are in agreement with the previous study conducted in Tanzania which reported food preferences and eating behavior to play major roles in Brucella infection in pastoral and agro-pastoral communities [5, 12]. Other studies in Africa also reported similar predictors for transmission of brucellosis, although the main predictors vary depending on customs and taboos of referred community [23, 24].

Regular contact with animal manure and contact with the placenta had increased odds of being seropositive for Brucella infection in the bivariate analysis model. However, contact with animal placenta was not associated with Brucella seropositivity in the multivariable logistic regression model. Some studies also reported direct contact with livestock excreta as a potential route of exposure to Brucella infection [12, 23]. Similarly, contact with animal placenta has been reported associated with brucellosis [25-28]. It is also documented that Brucella spp. from infected animals are found in animal excreta which serve as sources of humans infections [29]. There was no evidence from the analysis to explain the lack of independent association of Brucella infection with exposure to animal placenta. The potential interaction with other variables was not supported by the multivariable logistic regression model.

The study relied heavily upon self-reported information which is open to information bias, clustering of events and failure to recall. Participants could have missed out on some possible factors associated with the occurrence of brucellosis. Reporting error for some measures was reduced by asking participants to recall only events in the last 3 months. Despite the limitations encountered, this study has demonstrated some important factors associated with transmission of Brucella to humans in the Ngorongoro ecosystem. Our findings serve as considerable baseline data for prevention and control of the disease and associated adverse effect in pregnancy.

\section{Conclusion}

This study has found that brucellosis is an important public health problem among pregnant women in the area with interactions of humans; livestock and wildlife. The risk of infection increased with the preference of raw foodstuffs like animal blood, meat, and milk. These 
findings emphasize the need for interventional strategies to reduce the risk of exposure and improve early detection of infection in pregnant women.

\section{Supplementary information}

Supplementary information accompanies this paper at https://doi.org/10. 1186/s12879-020-4873-7.

Additional file 1. Interview questionnaire.

\section{Abbreviations}

ELISA: Enzyme-linked immunosorbent assay; IgG: Immunoglobulin G; IgM: Immunoglobulin M; MUHAS: Muhimbili University of Health and Allied Sciences; RBPT: Rose Bengal plate test

\section{Acknowledgments}

We are grateful to all pregnant women who participated in the study. We thank laboratory personnel at Wasso hospital and Central Veterinary Laboratory for technical support. Our sincere gratitude also goes to health workers at Wasso hospital for cooperation and assistance in recruitment and specimen collection.

\section{Authors' contributions}

RM and MVM were involved in conception and design of the study; RM participated in data collection, laboratory work and drafting the manuscript; MVM had overall coordination of the study; RM, MVM, and GMB contributed to the analysis and interpretation of data; MVM, UK, GMB, MMM, and AJ participated in write up and critically revising the manuscript. All authors read and approved the final version of the manuscript.

\section{Funding}

The funding for data collection and laboratory works were obtained from the Ministry of Health, Community Development, Gender, Elderly and Children. The funder had no role in the design of the study, collection, analysis, and interpretation of data and in writing the manuscript.

\section{Availability of data and materials}

The datasets used and analysed for the current study are available from the corresponding author on reasonable request.

\section{Ethics approval and consent to participate}

The ethical approval was obtained from the Senate Research and Publication Committee, the Institutional Review Board of Muhimbili University of Health and Allied Sciences (MUHAS). Permission to conduct the study was obtained from the District Director and hospital authorities where the study was conducted. Written informed consent was obtained from all patients before being enrolled in the study.

\section{Consent for publication}

Not applicable.

\section{Competing interests}

The authors declare that they have no competing interests.

\section{Author details}

'Manyara Regional Referral Hospital, Babati, Tanzania. ${ }^{2}$ Department of Microbiology and Immunology, Muhimbili University of Health and Allied Sciences, Dar es Salaam, Tanzania. ${ }^{3}$ Department of Pharmaceutical Microbiology, School of Pharmacy, Muhimbili University of Health and Allied, Dar es Salaam, Tanzania. ${ }^{4}$ Department of Microbiology and Immunology, Weill Bugando School of Medicine, Catholic University of Health and Allied Sciences, Mwanza, Tanzania.
Received: 1 August 2019 Accepted: 11 February 2020

Published online: 18 February 2020

\section{References}

1. Kurdoglu M, Adali E, Kurdoglu Z, Karahocagil MK, Kolusari A, Yildizhan R, Kucukaydin Z, Sahin HG, Kamaci M, Akdeniz H. Brucellosis in pregnancy: a 6year clinical analysis. Arch Gynecol Obstet. 2009;281(2):201-6.

2. Rujeni N, Mbanzamihigo L. Prevalence of brucellosis among women presenting with abortion/stillbirth in Huye, Rwanda. J Trop Med. 2014;2014: 740479

3. Godfroid J, Scholz HC, Barbier T, Nicolas C, Wattiau P, Fretin D, Whatmore AM, Cloeckaert A, Blasco JM, Moriyon I, et al. Brucellosis at the animal/ ecosystem/human interface at the beginning of the 21st century. Prev Vet Med. 2011;102(2):118-31

4. Ali S, Akhter S, Neubauer H, Scherag A, Kesselmeier M, Melzer F, Khan I, ElAdawy H, Azam A, Qadeer S, et al. Brucellosis in pregnant women from Pakistan: an observational study. BMC Infect Dis. 2016;16:468.

5. Swai ES, Schoonman L. Human brucellosis: seroprevalence and risk factors related to high risk occupational groups in Tanga municipality, Tanzania. Zoonoses Public Health. 2009:56(4):183-7.

6. Fyumagwa R, Wambura P, Mellau L, Hoare R. Seroprevalence of Brucella abortus in buffaloes and wildebeests in the Serengeti ecosystem: a threat to humans and domestic ruminants. Tanzania Vet J. 2009;26(2):62-7.

7. Mellau L, Kuya S, Wambura P. Seroprevalence of brucellosis in domestic ruminants in livestock-wildlife interface: a case study of Ngorongoro conservation area, Arusha, Tanzania. Tanzania Vet J. 2009;26(1):44-50.

8. Vilchez G, Espinoza M, D'Onadio G, Saona P, Gotuzzo E. Brucellosis in pregnancy: clinical aspects and obstetric outcomes. Int J Infect Dis. 2015:38:95-100.

9. Bosilkovski M, Dimzova M, Grozdanovski K. Natural history of brucellosis in an endemic region in different time periods. Acta Clin Croat. 2009;48(1):41-6.

10. Memish ZA, Balkhy HH. Brucellosis and international travel. J Travel Med. 2004;11(1):49-55.

11. Kunda J, Fitzpatrick J, Kazwala R, French NP, Shirima G, Macmillan A Kambarage D, Bronsvoort M, Cleaveland S. Health-seeking behaviour of human brucellosis cases in rural Tanzania. BMC Public Health. 2007:7:315.

12. John K, Fitzpatrick J, French N, Kazwala R, Kambarage D, Mfinanga GS, MacMillan A, Cleaveland S. Quantifying risk factors for human brucellosis in rural northern Tanzania. PLoS One. 2010;5(4):e9968.

13. Israel GD. Determining sample size; 1992.

14. Ruiz-Mesa JD, Sanchez-Gonzalez J, Reguera JM, Martin L, Lopez-Palmero S, Colmenero JD. Rose Bengal test: diagnostic yield and use for the rapid diagnosis of human brucellosis in emergency departments in endemic areas. Clin Microbiol Infect. 2005;11(3):221-5.

15. WHO. Brucellosis in humans and animals: World Health Organization; 2006. http://www.who.int/csr/resources/pBrucellosi/Brucellosi

16. Shirima GM, Kunda JS. Prevalence of brucellosis in the human, livestock and wildlife interface areas of Serengeti National Park, Tanzania. Onderstepoort J Vet Res. 2016;83(1):a1032

17. Thapa SMM. Sero prevalence of brucellosis in pregnant women visiting Gynaecology Department of Kathmandu Model Hospital, Kathmandu, Nepal. Natl J Health Sci. 2018;9(3):16-9.

18. Tumwine G, Matovu E, Kabasa JD, Owiny DO, Majalija S. Human brucellosis: sero-prevalence and associated risk factors in agro-pastoral communities of Kiboga District, Central Uganda. BMC Public Health. 2015;15:900.

19. Nigussie A, Hoag D, Alemu T. Women's workload and role in livestock production in pastoral and agro-pastoral communities of Ethiopia: the case of Afar. African J Agric Econ Rural Dev. 2014;2(4):138-46.

20. Assenga JA, Matemba LE, Muller SK, Malakalinga JJ, Kazwala RR. Epidemiology of Brucella infection in the human, livestock and wildlife interface in the KataviRukwa ecosystem, Tanzania. BMC Vet Res. 2015;11:189.

21. Hambolu D, Freeman J, Taddese HB. Predictors of bovine TB risk behaviour amongst meat handlers in Nigeria: a cross-sectional study guided by the health belief model. PLoS One. 2013:8(2):e56091.

22. Pappas G, Akritidis N, Bosilkovski M, Tsianos E. Brucellosis. N Engl J Med. 2005;352(22):2325-36.

23. Genene RDM, Yamuah L, Hiwot T, Teshome G, Asfawesen G, Abraham A Abdoel TH, Smits HL. Human brucellosis in traditional pastoral communities in Ethiopia. Int J Trop Med. 2009:4(2):59-64.

24. Adesokan HK, Alabi PI, Ogundipe MA. Prevalence and predictors of risk factors for Brucellosis transmission by meat handlers and traditional healers' risk practices in Ibadan, Nigeria. J Prev Med Hyg. 2016;57(3):E164-71. 
25. Bikas C, Jelastopulu E, Leotsinidis M, Kondakis X. Epidemiology of human brucellosis in a rural area of North-Western Peloponnese in Greece. Eur J Epidemiol. 2003;18(3):267-74.

26. Cooper CW. Risk factors in transmission of brucellosis from animals to humans in Saudi Arabia. Trans R Soc Trop Med Hyg. 1992;86(2):206-9.

27. Schelling E, Diguimbaye C, Daoud S, Nicolet J, Boerlin P, Tanner M, Zinsstag J. Brucellosis and Q-fever seroprevalences of nomadic pastoralists and their livestock in Chad. Prev Vet Med. 2003;61 (4):279-93.

28. Lim HS, Min YS. Lee HS: [investigation of a series of brucellosis cases in Gyeongsangbuk-do during 2003-2004]. J Prev Med Public Health. 2005;38(4):482-8.

29. Young EJ. Human brucellosis. Rev Infect Dis. 1983;5(5):821-42.

\section{Publisher's Note}

Springer Nature remains neutral with regard to jurisdictional claims in published maps and institutional affiliations.

Ready to submit your research? Choose BMC and benefit from:

- fast, convenient online submission

- thorough peer review by experienced researchers in your field

- rapid publication on acceptance

- support for research data, including large and complex data types

- gold Open Access which fosters wider collaboration and increased citations

- maximum visibility for your research: over $100 \mathrm{M}$ website views per year

At $\mathrm{BMC}$, research is always in progress.

Learn more biomedcentral.com/submissions 